\title{
Clinical Resistance Associated with a Novel MAP2K1 Mutation in a Patient with Langerhans Cell Histiocytosis
}

David O. Azorsa ${ }^{1,2}$, David W. Lee ${ }^{1,2}$, Daniel H. Wai ${ }^{1,2}$, Ranjan Bista ${ }^{1,2,3}$, Apurvi R. Patel ${ }^{1,2,3}$, Eiman Aleem ${ }^{1,2,4}$, Michael M. Henry ${ }^{2,3}$, Robert J. Arceci ${ }^{1,2,3, \uparrow}$

'Institute of Molecular Medicine at Phoenix Children's Hospital, Phoenix, AZ

${ }^{2}$ Department of Child Health, University of Arizona College of Medicine, Phoenix, AZ

${ }^{3}$ Center for Cancer and Blood Disorders, Phoenix Children's Hospital, Phoenix, AZ

${ }^{4}$ Faculty of Science, Alexandria University, Alexandria, Egypt

$\dagger$ Deceased June 8, 2015

Correspondence:

David O. Azorsa, Ph.D.

Institute of Molecular Medicine at Phoenix Children's Hospital

Department of Child Health

University of Arizona College of Medicine

475 N. Fifth St.

Phoenix, AZ 85004

Tel: $602-827-2529$

Fax: 602-827-2530

Email: dazorsa@email.arizona.edu

Word Count:

Abstract: 88/100

Main Text: 1,198/1200

Figures: 2

References: 20

Running Title: Novel MAP2K1/MEK1 mutation in LCH patient

Key Words: Langerhans Cell Histiocytosis, MAP2K1, mutation 


\section{Abbreviations}

ARAF proto-oncogene belonging to RAF family

BRAF proto-oncogene belonging to RAF family

BRAF V600E BRAF harboring an activating mutation at amino acid 600

ERK Signaling kinases ERK1 (MAPK3) and ERK2 (MAPK1)

LCH Langerhans cell histiocytosis

MAP2K1 Gene encoding MEK1

MAP3K1 Gene encoding MEK kinase (MEKK)

MEK1 Mitogen-activated protein kinase kinase; encoded by the MAP2K1 gene

MEK-MUT Mutated MEK1 harboring the MAP2K1 p.L98_K104>Q mutation

MEK-WT Wild-type MEK1

PET-CT Positron Emission Tomography/Computed Tomography

RAS Small GTPases involved in signaling including HRAS, KRAS and NRAS

RAF Kinases involved in signaling including ARAF, BRAF, an c-RAF 


\begin{abstract}
Patients with Langerhans cell histiocytosis ( $\mathrm{LCH}$ ) harbor $B R A F$ V600E and activating mutations of $M A P 2 K 1 / M E K 1$ in $50 \%$ and $25 \%$ of cases, respectively. We evaluated a patient with treatment refractory LCH for mutations in the RAS-RAF-MEK-ERK pathway and identified a novel mutation in the $M A P 2 K 1$ gene resulting in a p.L98_K104>Q deletion and predicted to be auto-activating. During treatment with the MEK inhibitor trametinib, the patient's disease showed significant progression. In vitro characterization of the MAP2K1 p.L98_K104>Q deletion confirmed its effect on cellular activation of the ERK pathway and drug resistance.
\end{abstract}




\section{Introduction}

Langerhans cell histiocytosis ( $\mathrm{LCH})$ is a rare disorder characterized by the clonal expansion of Langerhans cells and is associated with a wide range of clinical symptoms [1]. Genomic analysis of patients with LCH have identified several functionally relevant mutations [2], including $B R A F^{\mathrm{V} 600 \mathrm{E}}$, which are present in over $50 \%$ of $\mathrm{LCH}$ patients [3,4], MAP2K1 (MEK1) mutations, which occur in about $25 \%$ of patients [5-7], as well as mutations in $A R A F$ [8], and MAP3K1 [7]. The identification of the BRAF ${ }^{\mathrm{V} 600 \mathrm{E}}$ mutation in $\mathrm{LCH}$ has led to the application of targeted therapy[9], in particular the use of vemurafenib [10]. MAP2K1 mutations of $\mathrm{LCH}$ patients are activating mutations and mutually exclusive of the $B R A F^{\mathrm{V} 600 \mathrm{E}}$ mutation [6]. Mutations of genes in the RAS-RAF-MEK-ERK pathway in LCH suggest that targeted therapy with MEK inhibitors may benefit LCH patients. Studies of targeted therapy for MAP $2 K 1$ using trametinib have been done for several cancer types $[11,12]$ including histiocytosis $[13,14]$. Here, we describe an $\mathrm{LCH}$ patient harboring a novel mutation in $M A P 2 K 1$, who underwent treatment with trametinib resulting in disease progression, and subsequent functional analysis of the novel MAP2K1 mutation.

\section{Materials and Methods}

\section{Mutation Analysis}

A sample of lymph node from a patient diagnosed with LCH was sent to Foundation Medicine (Cambridge, MA) for FoundationOne ${ }^{\circledR}$ sequencing analysis of a 315-gene panel. 


\section{Cloning}

The wild type (MEK-WT) MEK1-GFP plasmid [15], a gift from Rony Seger (Addgene plasmid \#14746, Cambridge, MA), was used to create the MEK1 mutant (MEK-MUT). Briefly, a doublestranded 44 bp oligonucleotide (ThermoFisher; Waltham, MA) replicating the genomic deletion of the patient was substituted into the MEK-WT plasmid to generate the MEK-MUT version. Isolated clones of the MEK-MUT were sequence verified at the University of Arizona Genetics Core (Tucson, AZ).

\section{Cell Assays}

HEK293A cells (ThermoFisher) were grown in DMEM (Corning, Manassas, VA) supplemented with $10 \%$ FBS (ATLAS Biologicals, Ft. Collins, CO) and 2mM L-Glutamine (ThermoFisher) at $5 \% \mathrm{CO}_{2}$ and $37^{\circ} \mathrm{C}$. HEK293A cells were transiently transfected with purified MEK-WT or MEKMUT plasmids using Xtremegene-HP (Roche Life Sciences, Indianapolis, IN). At 48 hr, cells were treated with the inhibitors: Trametinib; U0126; MK-2206; or SCH772984 (all drugs from SelleckChem, Houston, TX) for $1 \mathrm{hr}$. Cells were collected for protein analysis. Stable expressing cells were generated through Neomycin selection using $0.4 \mathrm{mg} / \mathrm{ml} \mathrm{G} 418$ (ThermoFisher).

\section{Western Blot/AlphaLisa}

Cellular lysates from transfected cells were normalized for equal loading on gels and AlphaLisa (Perkin-Elmer; Waltham, MA) kit. Gels were transferred to PVDF membrane (Bio-Rad, Hercules, CA) and probed with antibodies against MEK/p-MEK; ERK/p-ERK; AKT/p-AKT or COX IV (Cell Signaling Technology, Danvers, MA). Blots were developed using ECL (ThermoFisher) and 
imaged. AlphaLisa assay for p-ERK (Perkin-Elmer) was analyzed as per manufacturer's instruction.

\section{Case Description}

A 16-year-old male was diagnosed with multifocal LCH primarily involving lymph nodes. The patient was treated with LCH-III therapy[16] and initially responded to treatment. One year later, the patient presented with painful right-sided neck swelling and a biopsy of the lesion confirmed recurrence of $\mathrm{LCH}$. The patient was then treated with the oral pan-AKT inhibitor afuresertib as part of a clinical trial [17]. The patient responded to afuresertib therapy and completed a total of 30 weeks of treatment (Fig. 1A). Several months later, the patient relapsed and was treated with cytarabine $150 \mathrm{mg} / \mathrm{m} 2 /$ day for a 5-day course. After two courses, the patient did not show a good response, and vincristine and steroids were added to the therapy. Afterward, the patient received two cycles of clofarabine, after which he was lost to follow-up. Three years after his initial diagnosis, the patient presented again with LCH symptoms and had cancer-related gene mutation analysis performed at Foundation Medicine. The genomic analysis identified a novel mutation in MAP2K1 (MEK1): an 18 bp deletion c293_310del in exon 3 resulting in a p.L98_K104>Q in-frame deletion (Fig. 1B). Based upon the gene target, the patient received the MEK inhibitor, trametinib, $2 \mathrm{mg}$ once daily. PET-CT whole body evaluation after eight weeks of treatment showed progressive disease (Fig. 1C). Treatment with trametinib was discontinued, and the patient was further treated with a combination of clofarabine and cytarabine for three cycles for disease control. Thereafter, the patient's disease was in control to obtain a haploidentical transplant, and more than a year after transplant the patient was doing well. 


\section{Results and Discussion}

In order to evaluate the function of the novel $M A P 2 K 1$ mutation, we duplicated the p.L98_K104>Q mutation using an expression construct for GFP-MEK [15]. HEK293A cells were transiently transfected with either the wild-type GFP-MEK construct (MEK-WT), the p.L98_K104>Q mutant (MEK-MUT) or left untransfected and were treated with MEK inhibitors U0126 or trametinib. Both MEK inhibitors were able to decrease p-ERK expression in untransfected cells and MEK-WT-expressing cells, but not in the MEK-MUT cells (Fig. 2A). MEK-MUT cells also expressed much higher levels of p-ERK than either MEK-WT or untransfected HEK293A cells using an AlphaLISA p-ERK assay (Fig. 2B). Furthermore, both MEK inhibitors greatly decreased p-ERK levels in untransfected and MEK-WT-expressing HEK293A cells, while having a mild effect on MEK-MUT cells. Transiently transfected cells were further grown in selection media to establish cells stably overexpressing either MEK-WT or MEK-MUT. These cells were similarly treated with MEK inhibitors U0126 and trametinib as well as the ERK inhibitor SCH772984 and the AKT inhibitor MK-2206. The MEK inhibitors decreased expression of p-ERK in the stably expressing MEK-WT cells but not in the stably expressing MEK-MUT cells (Fig. 2C). Taken together, these functional studies indicate that the MAP2K1 p.L98_K104>Q mutation leads to increased p-ERK activation that is unaffected by MEK inhibitors.

The p.L98_K104>Q mutation in MAP2K1 has not been previously described but it is found in a region of the $M A P 2 K 1$ gene where several other activating mutations have been found $[5,6,18,19]$ (Fig1D). In vitro functional studies show that the MEK inhibitor U0126 can inhibit ERK activation resulting from these mutations in this region of MAP2K1 [6]. Another study 
showed that the p.F53_Q58>L, p.Q58_E62del, and p.C121S/G128V mutations in MAP2K1 constituently activated ERK and were susceptible in vitro to MEK inhibitors including trametinib [20]. Interestingly, a recent report describes the complete remission of an $\mathrm{LCH}$ patient with a MAP2K1 p.E102-I103del mutation treated with trametinib [14]. The described MAP2K1 p.E102-I103del deletion involves six bases that fall inside the p.L98_K104>Q deletion and has been shown to be an activating mutation [5,6]. The difference in the response of these two patients, having similar but not identical $M A P 2 K 1$ mutations, to trametinib could be due to several factors including the structural change in MAP2K1 protein that the larger p.L98_K104>Q deletion would have on MAP2K1 activity or trametinib binding. The expression of the MAP2K1 p.L98_K104>Q mutation identified in this LCH patient leads to hyper-activated p-MAP2K1 and increases activation of p-ERK. As seen in these studies, and consistent with the clinical results, this activating $M A P 2 K 1$ mutation is not responsive to inhibition with MEK inhibitors, including trametinib. Further functional investigation of these $M A P 2 K 1$ mutations is

needed. Furthermore, it would be of interest to understand the role that the previous therapeutic treatment with afuresertib may have played in the development of this particular resistanceassociated mutation. These results emphasize the importance of the functional assessment of genomic data in assigning treatment for patients with $\mathrm{LCH}$ or other cancers, as well as provide evidence for choice of inhibitor in patients with this or similar mutations.

\section{Authorship Contributions}

Contribution: R.J.A. and D.W.L. designed the experimental approach. R.J.A., D.W.L., R.B. and M.M.H. performed the research and collected data. R.J.A., D.W.L., D.H.W., E.A. and D.O.A. 
analyzed the data. All authors were involved in interpretation of the data. D.O.A. and A.R.P. wrote the manuscript.

\section{Disclosure of Conflicts of Interest}

The authors declare no competing financial interests.

\section{Acknowledgments}

This manuscript is dedicated in memoriam of Robert J. Arceci. The authors thank the patient and the patient's family members. This work was funded by Sharon D. Lund Foundation, the University of Arizona COM-P Department of Child Health Mission Support, and the Phoenix Children's Hospital Foundation.

Correspondence: David O. Azorsa, Ph.D., Institute of Molecular Medicine at Phoenix Children's Hospital, Department of Child Health, University of Arizona College of Medicine, 475 N. Fifth St., Phoenix, AZ 85004: email: dazorsa@email.arizona.edu 


\section{References}

1. Harmon CM, Brown N. Langerhans Cell Histiocytosis: A Clinicopathologic Review and Molecular Pathogenetic Update. Archives of pathology \& laboratory medicine 2015;139(10):1211-1214.

2. Diamond EL, Durham BH, Haroche J, Yao Z, Ma J, Parikh SA, Wang Z, Choi J, Kim E, Cohen-Aubart F, Lee SC, Gao Y, Micol JB, Campbell P, Walsh MP, Sylvester B, Dolgalev I, Aminova O, Heguy A, Zappile P, Nakitandwe J, Ganzel C, Dalton JD, Ellison DW, Estrada-Veras J, Lacouture M, Gahl WA, Stephens PJ, Miller VA, Ross JS, Ali SM, Briggs SR, Fasan O, Block J, Heritier S, Donadieu J, Solit DB, Hyman DM, Baselga J, Janku F, Taylor BS, Park CY, Amoura Z, Dogan A, Emile JF, Rosen N, Gruber TA, Abdel-Wahab O. Diverse and Targetable Kinase Alterations Drive Histiocytic Neoplasms. Cancer Discov 2016;6(2):154-165.

3. Badalian-Very G, Vergilio JA, Degar BA, MacConaill LE, Brandner B, Calicchio ML, Kuo FC, Ligon AH, Stevenson KE, Kehoe SM, Garraway LA, Hahn WC, Meyerson M, Fleming MD, Rollins BJ. Recurrent BRAF mutations in Langerhans cell histiocytosis. Blood 2010;116(11):1919-1923.

4. Mehes G, Irsai G, Bedekovics J, Beke L, Fazakas F, Rozsa T, Kiss C. Activating BRAF V600E mutation in aggressive pediatric Langerhans cell histiocytosis: demonstration by allele-specific PCR/direct sequencing and immunohistochemistry. Am J Surg Pathol 2014:38(12);1644-1648.

5. Brown NA, Furtado LV, Betz BL, Kiel MJ, Weigelin HC, Lim MS, Elenitoba-Johnson KS. High prevalence of somatic MAP2K1 mutations in BRAF V600E-negative Langerhans cell histiocytosis. Blood 2014;124(10):1655-1658. 
6. Chakraborty R, Hampton OA, Shen X, Simko SJ, Shih A, Abhyankar H, Lim KP, Covington KR, Trevino L, Dewal N, Muzny DM, Doddapaneni H, Hu J, Wang L, Lupo PJ, Hicks MJ, Bonilla DL, Dwyer KC, Berres ML, Poulikakos PI, Merad M, McClain KL, Wheeler DA, Allen CE, Parsons DW. Mutually exclusive recurrent somatic mutations in MAP2K1 and BRAF support a central role for ERK activation in LCH pathogenesis. Blood 2014;124(19):3007-3015.

7. Nelson DS, van Halteren A, Quispel WT, van den Bos C, Bovee JV, Patel B, BadalianVery G, van Hummelen P, Ducar M, Lin L, MacConaill LE, Egeler RM, Rollins BJ. MAP2K1 and MAP3K1 mutations in Langerhans cell histiocytosis. Genes Chromosomes Cancer 2015;54(6):361-368 .

8. Nelson DS, Quispel W, Badalian-Very G, van Halteren AG, van den Bos C, Bovee JV, Tian SY, Van Hummelen P, Ducar M, MacConaill LE, Egeler RM, Rollins BJ. Somatic activating ARAF mutations in Langerhans cell histiocytosis. Blood 2014;123(20):31523155.

9. Abla O, Weitzman S. Treatment of Langerhans cell histiocytosis: role of BRAF/MAPK inhibition. Hematology American Society of Hematology Education Program 2015;2015:565-570.

10. Haroche J, Cohen-Aubart F, Emile JF, Donadieu J, Amoura Z. Vemurafenib as first line therapy in BRAF-mutated Langerhans cell histiocytosis. J Am Acad Dermatol 2015;73(1):e29-30.

11. Falchook GS, Lewis KD, Infante JR, Gordon MS, Vogelzang NJ, DeMarini DJ, Sun P, Moy C, Szabo SA, Roadcap LT, Peddareddigari VG, Lebowitz PF, Le NT, Burris HA, 3rd, Messersmith WA, O'Dwyer PJ, Kim KB, Flaherty K, Bendell JC, Gonzalez R, 
Kurzrock R, Fecher LA. Activity of the oral MEK inhibitor trametinib in patients with advanced melanoma: a phase 1 dose-escalation trial. Lancet Oncol 2012;13(8):782-789.

12. Kim KB, Kefford R, Pavlick AC, Infante JR, Ribas A, Sosman JA, Fecher LA, Millward M, McArthur GA, Hwu P, Gonzalez R, Ott PA, Long GV, Gardner OS, Ouellet D, Xu Y, DeMarini DJ, Le NT, Patel K, Lewis KD. Phase II study of the MEK1/MEK2 inhibitor Trametinib in patients with metastatic BRAF-mutant cutaneous melanoma previously treated with or without a BRAF inhibitor. Journal of Clinical Oncology 2013;31(4):482489.

13. Nordmann TM, Juengling FD, Recher M, Berger CT, Kalbermatten D, Wicki A, Paasinen-Sohns A, Cathomas G, Tzankov A, Daikeler T. Trametinib after disease reactivation under dabrafenib in Erdheim-Chester disease with both BRAF and KRAS mutations. Blood 2017;129(7):879-882.

14. Papapanagiotou M, Griewank KG, Hillen U, Schimming TT, Moeller LC, Führer D, Zimmer L, Roesch A, Sucker A, Schadendorf D, Livingstone E, Schilling B. TrametinibInduced Remission of an MEK1-Mutated Langerhans Cell Histiocytosis. JCO Precision Oncology 2017;(1):1-5.

15. Yao Z, Flash I, Raviv Z, Yung Y, Asscher Y, Pleban S, Seger R. Non-regulated and stimulated mechanisms cooperate in the nuclear accumulation of MEK1. Oncogene 2001;20(52):7588-7596.

16. Gadner H, Minkov M, Grois N, Potschger U, Thiem E, Arico M, Astigarraga I, Braier J, Donadieu J, Henter JI, Janka-Schaub G, McClain KL, Weitzman S, Windebank K, Ladisch S, Histiocyte S. Therapy prolongation improves outcome in multisystem Langerhans cell histiocytosis. Blood 2013;121(25):5006-5014. 
17. Arceci RJ, Allen CE, Dunkel IJ, Jacobsen E, Whitlock J, Vassallo R, Morris SR, Portnoy A, Reedy BA, Smith DA, Noble R, Murnane A, Cornfeld M, Rodriguez-Galindo C, Heaney ML, McClain K, Vaiselbuh S. A phase IIa study of afuresertib, an oral pan-AKT inhibitor, in patients with Langerhans cell histiocytosis. Pediatr Blood Cancer 2017;64(5):e26325.

18. Alayed K, Medeiros LJ, Patel KP, Zuo Z, Li S, Verma S, Galbincea J, Cason RC, Luthra R, Yin CC. BRAF and MAP2K1 mutations in Langerhans cell histiocytosis: a study of 50 cases. Hum Pathol 2016;52:61-67.

19. Zeng K, Ohshima K, Liu Y, Zhang W, Wang L, Fan L, Li M, Li X, Wang Z, Guo S, Yan Q, Guo Y. BRAFV600E and MAP2K1 mutations in Langerhans cell histiocytosis occur predominantly in children. Hematol Oncol 2017;35(4):845-851.

20. Lee LH, Gasilina A, Roychoudhury J, Clark J, McCormack FX, Pressey J, Grimley MS, Lorsbach R, Ali S, Bailey M, Stephens P, Ross JS, Miller VA, Nassar NN, Kumar AR. Real-time genomic profiling of histiocytoses identifies early-kinase domain BRAF alterations while improving treatment outcomes. JCI insight 2017;2(3):e89473. 


\section{Figure Legends}

Figure 1: Identification of a novel mutation in $M A P 2 K 1(M E K 1)$ in a patient with Langerhans Cell Histiocytosis. (A) PET scan of LCH patient prior to treatment with afuresertib and subsequent scans, at both 6 and 9 months post AKT inhibitor treatment, showing partial response. Written informed consent was provided for publication of the images. (B) Sequencing analysis of a sample from the $\mathrm{LCH}$ patient indicates an amino acid deletion/change (L98_K104>Q) due to a 18bp deletion in exon 3 of $M A P 2 K 1$ (MEK1). This region of the MEK protein corresponds to the p-loop binding site for phosphorylation of serines 217/222 (p-MEK). (C) PET scan of the $\mathrm{LCH}$ patient prior to treatment with trametinib and 8 weeks post Trametinib treatment. (D) Mutations in MAP2K1 protein that have been identified in LCH patient samples.

\section{Figure 2: Functional analysis of the L98_K104>Q mutation of MAP2K1 (MEK1). (A)}

Western blot analysis of untransfected HEK293A cells (293A), HEK293A transiently transfected with wild-type MAP2K1 (MEK-WT) and HEK293A transiently transfected with MAP2K1 containing the L98_K104>Q mutation (MEK-MUT) treated with 100 nM trametinib (T), or 30 $\mu \mathrm{M} \mathrm{U} 0126(\mathrm{U})$ for $1 \mathrm{hr}$. Lysates from each treatment were analyzed for protein expression using antibodies to p-ERK, total ERK, pMEK and total MEK. Antibody to COX IV was used as a loading control. Western blot panel shows increased expression of the MEK-WT and MEKMUT transfectants. The p-MEK-MUT has a 2-3 fold increase vs. p-MEK-WT resulting in a significant activation of p-ERK in the MUT samples. For 293A and MEK-WT, both U0126 and Trametinib show loss of activation of p-ERK by inhibiting p-MEK expression. The MEK-MUT form shows no sensitivity to either MEK inhibitor. (B) AlphaLisa analysis of p-ERK activation 
levels. Cell lysates (5 $\mu \mathrm{g}$ protein/sample) used in the western blots were analyzed for p-ERK levels using a double antibody AlphaLisa assay (Perkin Elmer) and results normalized to untreated 293A cell lysate. Similar to the western blot results, the AlphaLISA shows p-ERK activation in the 293A and MEK-WT samples is completely inhibited by both U0126 and Trametinib. The transient MEK-MUT showed no sensitivity to trametinib compared to no drug treatment, while showing partial inhibition by U0126. (C) Analysis of MEK-MUT activity in stably expressing cells. Cells transfected with either MEK-WT or MEK-MUT were grown in media containing G418 for generating stable expressing cells. Stably expressing MEK-WT or MEK-MUT were treated with no drugs (ND), $30 \mu \mathrm{M}$ U0126 (U), $100 \mathrm{nM}$ trametinib (T), the ERK inhibitor SCH772984 (E) at $200 \mathrm{nM}$, and the AKT inhibitor MK-2206 2HCl (A) at 100 nM. Western blot analysis of p-ERK expression showed a similar pattern to that of the transient samples except for decreased expression levels of transfected MEK and transfected p-MEK. The MEK inhibitors U0126 and trametinib inhibited p-ERK activation in MEK-WT cells but not in MEK-MUT cells as with the transient transfected cells. 
Figure 1

A
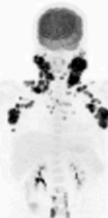

i.

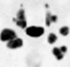

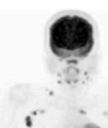

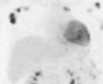

i.

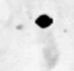

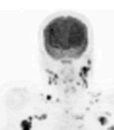

5. 1

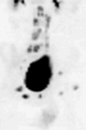

R L

9 mo. Post

AKT Inhibitor
C
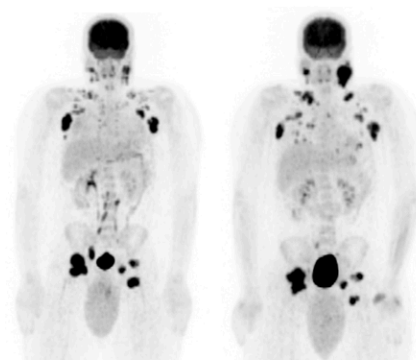

L

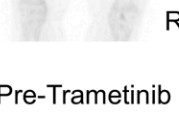

L

8 wks. Post

Trametinib
B

MEK WT GTCATGGCCAGAAAGCTAATTCATCTGGAGATCAAACCCGCAATCCGgAaC

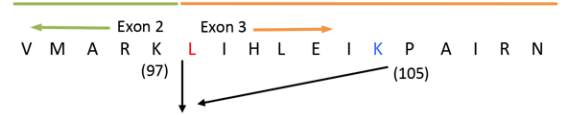

MEK MUT GTCATGgCCAgaAagCAACCCGCAATCCGgAaC

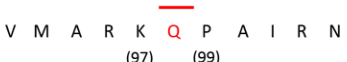

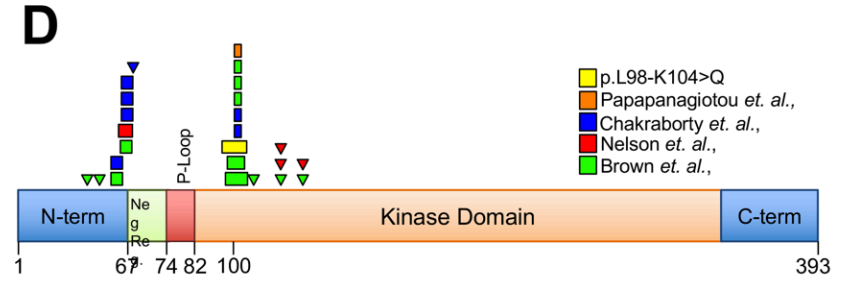

MAP2K1 (MEK1) 
Figure 2

A

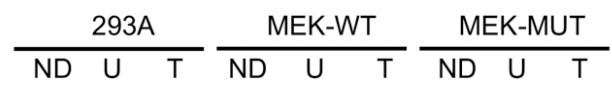

PERK $=$

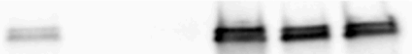

ERK

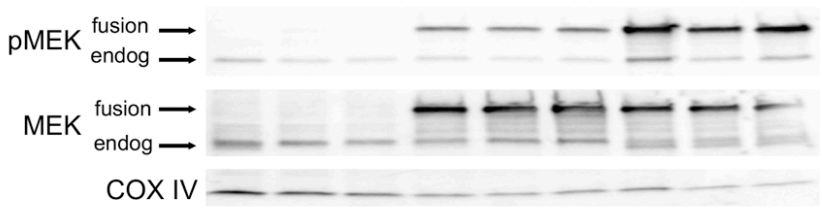

B

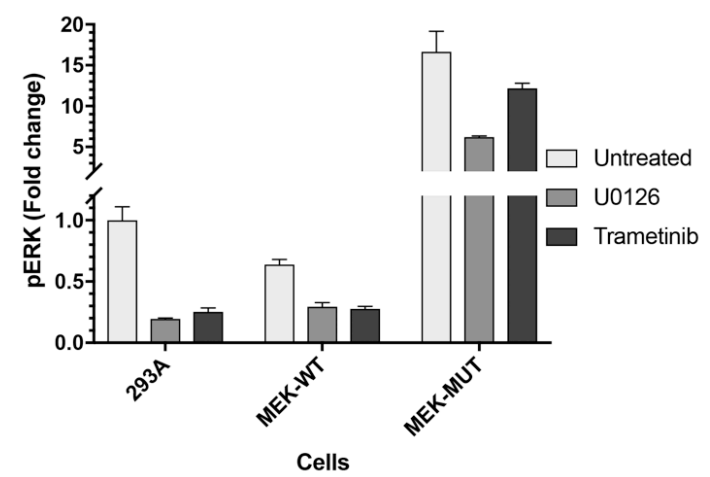

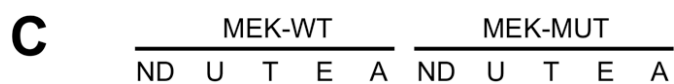

p-ERK $=\quad==\approx=\approx=0$

$\mathrm{ERK}=\equiv= \pm=\equiv=\equiv=$

p-AKT $-\cdots-\cdots-\cdots$

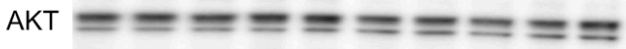

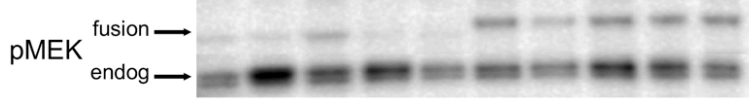

MEK $_{\text {endog }}^{\text {fusion } \rightarrow-~}$

coxIV 